\title{
Comparative Study of Robust Control Strategies for a Dfig-Based Wind Turbine
}

\author{
Mohamed BENKAHLA, Rachid TALEB, Zinelaabidine BOUDJEMA \\ Electrical Engineering Department, Hassiba Benbouali University \\ Laboratoire Génie Electrique et Energies Renouvelables (LGEER) \\ Chlef, Algeria
}

\begin{abstract}
Conventional vector control configurations which use a proportional-integral (PI) regulator for the powers DFIGs driven have some drawbacks such as parameter tuning difficulties, mediocre dynamic performances and reduced robustness. So, based on analysis of the DFIG model, fed by a direct AC-AC converter, two nonlinear algorithms: sliding mode and adaptive fuzzy logic is used to control independently active and reactive powers provided by the stator side of the DFIG to the grid. Their respective performances are compared with the conventional PI controller regarding reference tracking, response to sudden speed variation and robustness against machine parameters variations.
\end{abstract}

Keywords-Wind turbine (WT); doubly fed induction generator (DFIG); sliding mode controller (SMC); PI controller; adaptive fuzzy logic controller (AFLC)

\section{INTRODUCTION}

Wind energy is the most promising renewable source of Electrical power generation for the future. Many countries promote the wind power technology through various national Programs and market incentives. Wind energy technology has evolved rapidly over the past three decades with increasing rotor diameters and the use of sophisticated power electronics to allow operation at variable speed [1].

Doubly fed induction generator (DFIG) is one of the most popular variable speed wind turbines in use nowadays. It is usually supplied by a voltage source inverter. However, currently the three phase matrix converters have received considerable attention because they may become a good alternative to voltage-source inverter Pulse-Width-Modulation (PWM) topology. The matrix converter provides bi-directional power flow, nearly sinusoidal input/output waveforms, and a controllable input power factor [2]. Furthermore, the matrix converter allows a compact design due to the lack of dc-link capacitors for energy storage. Consequently, in this work, a three-phase matrix converter is used to drive the DFIG.

Many research works have been presented with different control schemes of DFIG. These control diagrams are usually based on vector control notion with conventional PI controllers as proposed in $[3,4]$. The similar conventional controllers are also used to realize control techniques of DFIG when grid faults appear like unbalanced voltages [5, 6] and voltage dips [7]. It has also been shown in [8,9] that glimmer problems could be resolved with suitable control strategies. Many of these works prove that stator reactive power control can be an adapted solution to these diverse problems.
In recent years, the sliding mode control (SMC) Methodology has been widely used for robust control of nonlinear systems. Sliding mode control, based on the theory of variable structure systems (VSS), has attracted a lot of research on control systems for the last two decades. It achieves robust control by adding a discontinuous control signal across the sliding surface, satisfying the sliding condition. Nevertheless, this type of control has an essential disadvantage, which is the chattering phenomenon caused by the discontinuous control action. In order to overcome these difficulties, several modifications to the original sliding control law have been proposed, the most popular being the boundary layer approach [10].

Fuzzy logic is a technology based on engineering experience and observations. In fuzzy logic, an exact mathematical model is not necessary because linguistic variables are used to define system behavior rapidly.

This work is organized as follows. We briefly review the modelling of the device studied in Section II. In Section III we present the field oriented control of the DFIG. Section IV provides the control of stator active and reactive powers of the DFIG by using three different controllers: PI, SMC and AFLC. In Section V, The three controllers are compared regarding reference power tracking, sensitivity to perturbations and robustness against machine parameters variations. Finally, a summary of the results is presented in the Conclusion.

\section{SySTEM MODELING}

\section{A. Wind turbine model}

For a horizontal axis wind turbine, the mechanical power captured from the wind is given by [11]:

$P_{t}=\frac{1}{2} C_{P}(\lambda, \beta) \pi R^{2} \rho v^{3}$

where, $R$ is the radius of the turbine $(\mathrm{m}), \rho$ is the air density $\left(\mathrm{kg} / \mathrm{m}^{3}\right), v$ is the wind speed $(\mathrm{m} / \mathrm{s})$, and $C_{P}$ is the power coefficient which is a function of both tip speed ratio $\lambda$, and blade pitch angle $\beta$ (deg). In this work, the $C_{P}$ equation is approximated using a nonlinear function according to [12].

$$
C_{P}=(0.5-0.167)(\beta-2) \sin \left[\frac{\pi(\lambda+0.1)}{18.5-0.3(\beta-2)}\right]-0.0018(\lambda-3)(\beta-2)
$$

The tip speed ratio is given by: 
$\lambda=\frac{\Omega_{t} R}{v}$

where $\Omega_{t}$ is the angular velocity of Wind Turbine.

\section{B. The matrix converter model}

The matrix converter performs the power conversion directly from $\mathrm{AC}$ to $\mathrm{AC}$ without any intermediate dc link. It is very simple in structure and has powerful controllability.

The converter consists of a matrix of bi-directional switches linking two independent three-phase systems. Each output line is linked to each input line via a bi-directional switch. Fig. 1 shows the basic diagram of a matrix converter.

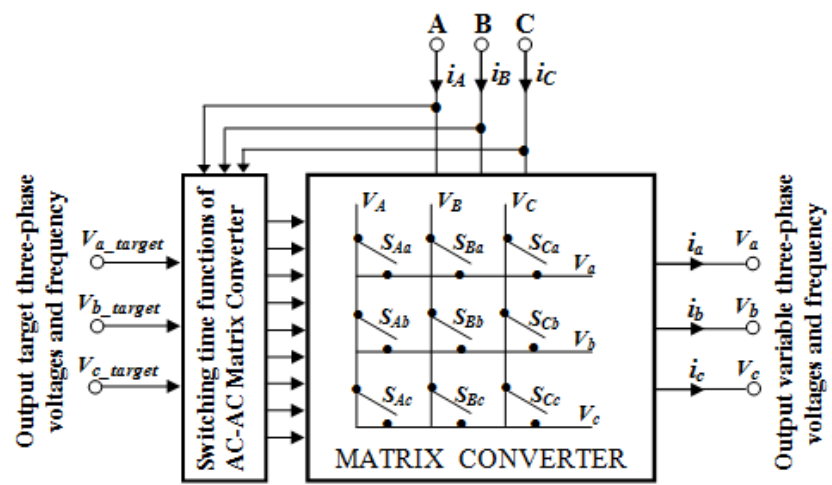

Fig. 1. Schematic representation of the matrix converter

The switching function of a switch $S_{m n}$ in Fig. 1 is given by:

$S_{m n}=\left\{\begin{array}{ll}1 & S_{m n} \text { closed } \\ 0 & S_{m n} \text { open }\end{array} \quad m \in\{A, B, C\}, n \in\{a, b, c\}\right.$

The mathematical expression that represents the operation of the matrix converter in figure 1 can be written as:

$\left[\begin{array}{c}V_{a} \\ V_{b} \\ V_{c}\end{array}\right]=\left[\begin{array}{lll}S_{A a} & S_{A b} & S_{A c} \\ S_{B a} & S_{B b} & S_{B c} \\ S_{C a} & S_{C b} & S_{C c}\end{array}\right] \cdot\left[\begin{array}{c}V_{A} \\ V_{B} \\ V_{C}\end{array}\right]$

$\left[\begin{array}{c}i_{A} \\ i_{B} \\ i_{C}\end{array}\right]=\left[\begin{array}{lll}S_{A a} & S_{B a} & S_{C a} \\ S_{A b} & S_{B b} & S_{C b} \\ S_{A c} & S_{B c} & S_{C c}\end{array}\right]^{T} \cdot\left[\begin{array}{c}i_{a} \\ i_{b} \\ i_{c}\end{array}\right]$

To determine the behavior of the matrix converter at output frequencies well below the switching frequency, a modulation duty cycle can be defined for each switch.

The input/output relationships of voltages and currents are related to the states of the nine switches and can be expressed as follows:

$\left[\begin{array}{c}V_{a} \\ V_{b} \\ V_{c}\end{array}\right]=\left[\begin{array}{lll}k_{A a} & k_{A b} & k_{A c} \\ k_{B a} & k_{B b} & k_{B c} \\ k_{C a} & k_{C b} & k_{C c}\end{array}\right] \cdot\left[\begin{array}{c}V_{A} \\ V_{B} \\ V_{C}\end{array}\right]$
$\left[\begin{array}{l}i_{A} \\ i_{B} \\ i_{C}\end{array}\right]=\left[\begin{array}{lll}k_{A a} & k_{B a} & k_{C a} \\ k_{A b} & k_{B b} & { }^{k} C b \\ k_{A c} & k_{B c} & { }^{k} C c\end{array}\right]^{T} \cdot\left[\begin{array}{c}i_{a} \\ i_{b} \\ i_{c}\end{array}\right]$

with: $0 \leq k_{m n} \leq 1, \quad m=A, B, C, n=a, b, c$

The variables $k_{m n}$ are the duty cycles of the nine switches $S_{m n}$ and can be represented by the duty-cycle matrix $k$. In order to prevent a short circuit on the input side and ensure uninterrupted load current flow, these duty cycles must satisfy the three following constraint conditions:

$k_{A a}+k_{A b}+k_{A c}=1$

$k_{B a}+k_{B b}+k_{B c}=1$

$k_{C a}+k_{C b}+k_{C c}=1$

The high-frequency synthesis technique introduced by Venturini (1980) and Alesina and Venturini (1988), allows a control of the $S_{m n}$ switches so that the low frequency parts of the synthesized output voltages $\left(V_{a}, V_{b}\right.$ and $\left.V_{c}\right)$ and the input currents $\left(i_{A}, i_{B}\right.$ and $\left.i_{C}\right)$ are purely sinusoidal with the prescribed values of the output frequency, the input frequency, the displacement factor and the input amplitude. The output voltage is given by :

$\left[\begin{array}{l}V_{a} \\ V_{b} \\ V_{c}\end{array}\right]=\left[\begin{array}{ccc}1+2 \delta \cos \alpha & 1+2 \delta \cos \left(\alpha-\frac{2 \pi}{3}\right) & 1+2 \delta \cos \left(\alpha-\frac{4 \pi}{3}\right) \\ 1+2 \delta \cos \left(\alpha-\frac{4 \pi}{3}\right) & 1+2 \delta \cos \alpha & 1+2 \delta \cos \left(\alpha-\frac{2 \pi}{3}\right) \\ 1+2 \delta \cos \left(\alpha-\frac{2 \pi}{3}\right) & 1+2 \delta \cos \left(\alpha-\frac{4 \pi}{3}\right) & 1+2 \delta \cos \alpha\end{array}\right] \cdot\left[\begin{array}{l}V_{A} \\ V_{B} \\ V_{C}\end{array}\right]$

where $\left\{\begin{array}{l}\alpha=\omega_{m}+\theta \\ \omega_{m}=\omega_{\text {output }}-\omega_{\text {input }}\end{array}\right.$

The running matrix converter with Venturini algorithm generates at the output a three-phases sinusoidal voltages system having in that order pulsation $\omega_{m}$, a phase angle $\theta$ and amplitude $\delta . V_{s}(0<\delta<0.866$ with modulation of the neural $)$ [13].

\section{Doubly fed induction generator modeling}

For a doubly fed induction machine, the Concordia and Park transformation's application to the traditional $a, b, c$ model allows to write a dynamic model in a $d-q$ reference frame as follows:

$$
\left\{\begin{array}{l}
V_{d s}=R_{s} I_{d s}+\frac{d}{d t} \psi_{d s}-\omega_{s} \psi_{q s} \\
V_{q s}=R_{s} I_{q s}+\frac{d}{d t} \psi_{q s}+\omega_{s} \psi_{d s} \\
V_{d r}=R_{r} I_{d r}+\frac{d}{d t} \psi_{d r}-\omega_{r} \psi_{q r} \\
V_{q r}=R_{r} I_{q r}+\frac{d}{d t} \psi_{q r}+\omega_{r} \psi_{d r}
\end{array},\left\{\begin{array}{l}
\psi_{d s}=L_{S} I_{d s}+M I_{d r} \\
\psi_{q s}=L_{s} I_{q s}+M I_{q r} \\
\psi_{d r}=L_{r} I_{d r}+M I_{d s} \\
\psi_{q r}=L_{r} I_{q r}+M I_{q s}
\end{array}\right.\right.
$$

The stator and rotor angular velocities are linked by the following relation : $\omega_{s}=\omega+\omega_{r}$. This electrical model is completed by the mechanical equation: 
$C_{e m}=C_{r}+J \frac{d \Omega}{d t}+f \Omega$

where the electromagnetic torque $C_{e m}$ can be written as a function of stator flux and rotor currents:

$$
C_{e m}=p \frac{M}{L_{S}}\left(\psi q s^{I} d r-\psi d s I_{q r}\right)
$$

\section{FIELD ORIENTED CONTROL OF THE DFIG}

In order to easily control the production of electricity by the wind turbine, we will carry out an independent control of active and reactive powers by orientation of the stator flux.

Since the stator is directly connected to the grid and the stator flux can be considered constant, and if the voltage dropped in the stator resistance has been neglected, the voltage equations, flux equations, currents equations and stator active and reactive powers equations can be simplified in study state as: If the stator flux is linked to the d-axis of the frame we have:

$\psi_{d s}=\psi_{s}$ and $\psi_{q s}=0$

And the electromagnetic torque can then be expressed as follows:

$$
C_{e m}=-p \frac{M}{L_{s}} I_{q r} \psi d s
$$

by substituting Eq. 18 in Eq. 15, the following rotor flux equations are obtained:

$\left\{\begin{array}{l}\psi_{s}=L_{s} I_{d s}+M I_{d r} \\ 0=L_{S} I_{q s}+M I_{q r}\end{array}\right.$

In addition, the stator voltage equations are reduced to:

$$
\left\{\begin{array}{l}
V_{d s}=0 \\
V_{q s}=\omega_{s} \psi_{s}
\end{array}\right.
$$

By supposing that the electrical supply network is stable, having for simple voltage $V_{s}$, that led to a stator flux $\psi_{s}$ constant. This consideration associated with Eq. 19 shows that the electromagnetic torque only depends on the $q$-axis rotor current component. Using Eq. 20, a relation between the stator and rotor currents can be established:

$$
\left\{\begin{array}{l}
I_{d s}=-\frac{M}{L_{s}} I_{d r}+\frac{\psi_{s}}{L_{s}} \\
I_{q s}=-\frac{M}{L_{S}} I_{q r}
\end{array}\right.
$$

The stator active and reactive powers are written:

$$
\left\{\begin{array}{l}
P_{s}=V_{d s} I_{d s}+V_{q s} I_{q s} \\
Q_{s}=V_{q s} I_{d s}-V_{d s} I_{q s}
\end{array}\right.
$$

By using Eqs. 14, 15, 12 and 22, the statoric active and reactive power, the rotoric fluxes and voltages can be written versus rotoric currents as:

$$
\begin{aligned}
& \left\{\begin{array}{l}
P_{s}=-\frac{\omega_{s} \psi_{s} M}{L_{S}} I_{q r} \\
Q_{S}=-\frac{\omega_{s} \psi_{s} M}{L_{s}} I_{d r}+\frac{\omega_{s} \psi_{s}{ }^{2}}{L_{s}}
\end{array}\right. \\
& \left\{\begin{array}{l}
\psi_{d r}=\left(L_{r}-\frac{M^{2}}{L_{S}}\right) I_{d r}+\frac{M \psi_{s}}{L_{S}} \\
\psi_{q r}=\left(L_{r}-\frac{M^{2}}{L_{s}}\right) I_{q r}
\end{array}\right. \\
& \left\{\begin{array}{l}
V_{d r}=R_{r} I_{d r}+\left(L_{r}-\frac{M^{2}}{L_{S}}\right) \frac{d I_{d r}}{d t}-g \omega_{s}\left(L_{r}-\frac{M^{2}}{L_{S}}\right) I_{q r} \\
V_{q r}=R_{r} I_{q r}+\left(L_{r}-\frac{M^{2}}{L_{S}}\right) \frac{d I_{q r}}{d t}+g \omega_{s}\left(L_{r}-\frac{M^{2}}{L_{S}}\right) I_{d r}+g \omega_{s} \frac{M \psi_{s}}{L_{S}}
\end{array}\right.
\end{aligned}
$$

In steady state, the second derivative terms of the two equations in 26 are nil. We can thus write:

$$
\left\{\begin{array}{l}
V_{d r}=R_{r} I_{d r}-g \omega_{s}\left(L_{r^{-}} \frac{M^{2}}{L_{s}}\right) I_{q r} \\
V_{q r}=R_{r} I_{q r}+g \omega_{s}\left(L_{r^{-}} \frac{M^{2}}{L_{s}}\right) I_{d r}+g \omega_{s} \frac{M \psi_{s}}{L_{s}}
\end{array}\right.
$$

The third term, which constitutes cross-coupling terms, can be neglected because of their small influence. These terms can be compensated by an adequate synthesis of the regulators in the control loops.

\section{CONTROLLERS SYNTHESIS}

In this section, we have chosen to compare the performances of the DFIG with three different controllers: PI, SMC and AFLC.

Based on relations (23) and (25), the control system can be designed as shown in Fig. 2. The blocks $R_{1}, R_{2}, R_{3}$ and $R_{4}$ represent respectively the stator powers and the rotor currents regulators.

\section{A. PI controller synthesis}

This controller is simple to elaborate. Figure 2 shows the block diagram of the system implemented with this controller. The terms $k_{p}$ and $k_{i}$ represent respectively the proportional and integral gains. The quotient $B / A$ represents the transfer function to be controlled, where $A$ and $B$ are presently defined as follows:

$$
A=L_{S} R_{r}+s . L_{S}\left(L_{r}-\frac{M^{2}}{L_{S}}\right) \text { and } B=\omega_{s} \psi_{s} M
$$

The regulator terms are calculated with a polecompensation method. The time response of the controlled system will be fixed at $10 \mathrm{~ms}$. This value is sufficient for our application and a lower value might involve transients with important overshoots. Fig. 3 shows the system with PI controller, the calculated terms are:

$$
k_{p}=\frac{1}{1 \times 10^{-3}} \frac{L_{S}\left(L_{r}-\frac{M^{2}}{L_{S}}\right)}{M \omega_{s} \psi_{s}}, k_{i}=\frac{1}{1 \times 10^{-3}} \frac{L_{S} R_{r}}{M \omega_{s} \psi_{s}}
$$


It is important to specify that the pole compensation is not the only method to calculate a PI regulator but it is simple to elaborate with a first-order transfer-function and it is sufficient in our case.

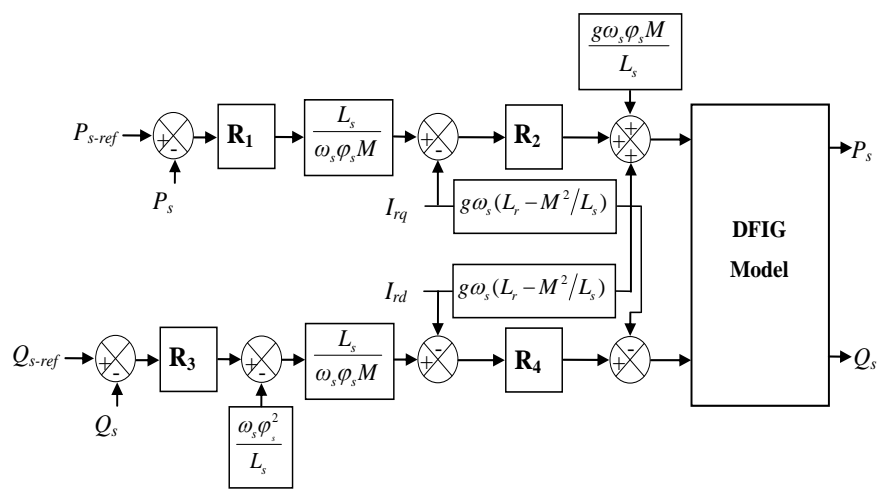

Fig. 2. Power control of the DFIG

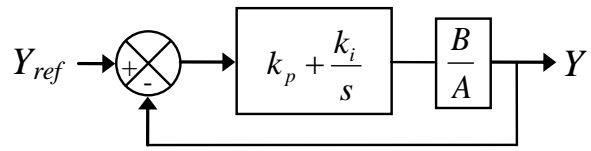

Fig. 3. System with PI controller

\section{B. Sliding mode controller (SMC)}

The sliding mode technique is developed from variable structure control to solve the disadvantages of other designs of nonlinear control systems. The sliding mode is a technique to adjust feedback by previously defining a surface. The system which is controlled will be forced to that surface, then the behavior of the system slides to the desired equilibrium point.

The main feature of this control is that it only needs to drive the error to a "switching surface". In this study, the errors between the measured and references stator powers have been chosen as sliding mode surfaces, so the following expression can be written [14].

$$
\left\{\begin{array}{l}
S_{c}(P)=P_{S-r e f}-P_{S-m e s} \\
S_{c}(Q)=Q_{S-r e f}-Q_{S-m e s}
\end{array}\right.
$$

the first derivative of Eq. (29), gives:

$$
\left\{\begin{array}{l}
\dot{S}_{c}(P)=\dot{P}_{S-r e f}-\dot{P}_{S-m e s} \\
\dot{S}_{c}(Q)=\dot{Q}_{S-r e f}-\dot{Q}_{S-m e s}
\end{array}\right.
$$

we replace (23) in (30), we obtain:

$$
\left\{\begin{array}{l}
\dot{S}_{c}(P)=\dot{P}_{S-r e f}+\frac{\omega_{S} \varphi_{S} M}{L_{S}} \dot{I}_{q r} \\
\dot{S}_{c}(Q)=\dot{Q}_{S-r e f}+\frac{\omega_{S} \varphi_{S} M}{L_{S}} \dot{I}_{d r}-\frac{\omega_{S} \varphi_{S}^{2}}{L_{S}}
\end{array}\right.
$$

We pull derivatives of currents $I_{d r}$ and $I_{q r}$ of the Eq. (25) replaced in the Eq. (31), and during the sliding mode and in steady state, $S_{c}(P)=S_{c}(Q)=0$ and $\dot{S}_{c}(P)=\dot{S}_{c}(Q)=0$, we find equivalent command $I_{d r-e q}$ and $I_{q r-e q}$ :

$$
\begin{aligned}
& \left\{\begin{array}{l}
I_{d r-e q}=Q_{S-r e f} \frac{L_{S} \sigma L_{r}}{V_{S} M R_{r}}+\left(\frac{1}{R_{r}} v_{d r}-\frac{L_{S} \sigma \omega_{r}}{V_{S} M R_{r}} I_{q r}\right) \\
I_{q r-e q}=P_{S-r e f} \frac{L_{S} \sigma L_{r}}{V_{S} M R_{r}}+\left(\frac{1}{R_{r}} v_{q r}-\frac{L_{r} \sigma \omega_{r}}{R_{r}} I_{d r}-g M \frac{V_{S}}{R_{r} L_{S}}\right)
\end{array}\right. \\
& \sigma=1-\frac{M^{2}}{L_{S} L_{r}}
\end{aligned}
$$

To obtain good executions, dynamics and commutations around surfaces, the control vector is written as follows:

$$
\left\{\begin{array}{l}
I_{d r-n}=K_{d r} \cdot \operatorname{sign}\left(S_{c}\left(Q_{S}\right)\right) \\
I_{q r-n}=K_{q r} \cdot \operatorname{sign}\left(S_{c}\left(P_{S}\right)\right)
\end{array}\right.
$$

The sliding mode will exist only if the following condition is verified:

$$
S \cdot \dot{S}<0
$$

\section{Adaptive fuzzy logic controller (AFLC)}

Gain scheduling means a technique where PI controller parameters are tuned during control of the system in a predefined way [15], it enlarges the operation area of linear controller (PI) to perform well also with a nonlinear system. The diagram of this technique is illustrated in Fig. 4.

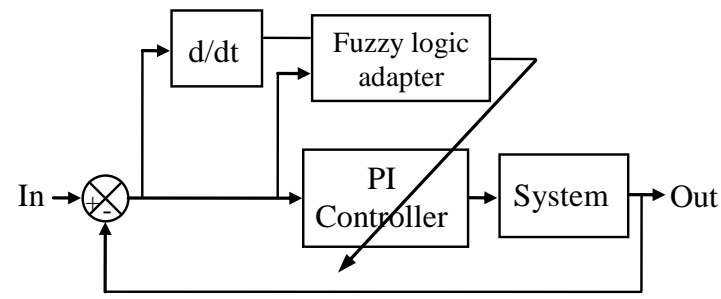

Fig. 4. Principle of adaptation of PI by fuzzy logic

The fuzzy inference mechanism adjusts the PI parameters and generates new parameters during process control, so that the fuzzy logic adapts the PI parameters to operating conditions based on the error and its first time difference. The parameters of the PI controller used in the direct chain $K_{p}$ and $K_{i}$ are normalized into the range between zero and one by using the following linear transformations [16]:

$$
\left\{\begin{array}{l}
K_{p}^{\prime}=\left(K_{p}-K_{p-\min }\right) /\left(K_{p-\max }-K_{p-\min }\right) \\
K_{i}^{\prime}=\left(K_{i}-K_{i-\min }\right) /\left(K_{i-\max }-K_{i-\min }\right)
\end{array}\right.
$$

The inputs of the fuzzy adapter are: The error $e$ and the derivative of error $\mathrm{d} e$, the outputs are: the normalized value of the proportional action $K_{p}^{\prime}$ and the normalized value of the integral action $K_{i}^{\prime}$.

The problem of selecting the suitable fuzzy controller rules remain relying on expert knowledge and try and error tuning methods. The fuzzy subsets of the input variables are defined as follows: $N B$ Negative Big, $N M$ Negative Middle, $N S$ Negative Small, EZ Equal Zero, PS Positive Small, PM Positive Middle, $P B$ Positive Big. The fuzzy subsets of the output variables are defined as follows: $B$ Big, $S$ Small. 
The membership functions for $e$ inputs and $\mathrm{d} e$ are defined in the range $[-1,1]$ (Fig. 5). And memberships functions for the outputs are defined in the interval $[0,1]$ (Fig. 6).
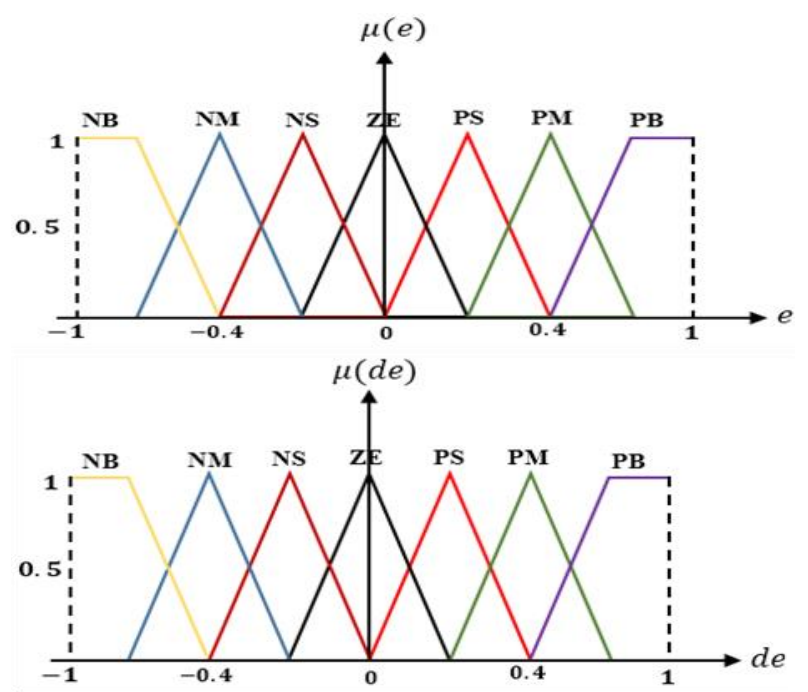

Fig. 5. Function of membership for $e$ and $d e$

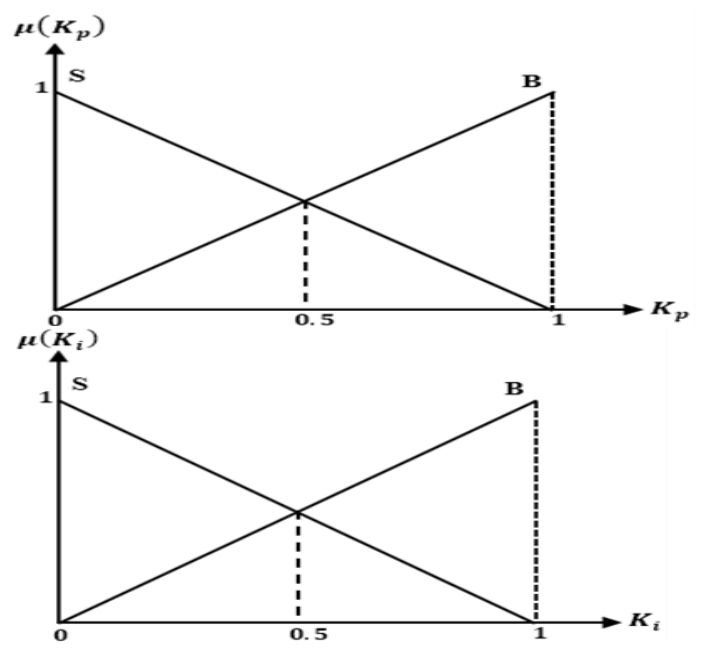

Fig. 6. Function of membership for $K p$ and $K i$

The fuzzy rules may be extracted from operator's expertise or based on the step response of the process [15]. The tuning rules for $K_{p}^{\prime}$ and $K_{i}^{\prime}$ are given in Tables 1 and 2 respectively.

TABLE I. BASIS OF RULES FOR THE OUTPUT $\mathrm{K}_{\mathrm{P}}$

\begin{tabular}{|l|l|l|l|l|l|l|l|}
\hline $\mathrm{e}$ & $N B$ & $N M$ & $N S$ & $Z E$ & $P S$ & $P M$ & $P B$ \\
\hline$N B$ & $\mathrm{~B}$ & $\mathrm{~B}$ & $\mathrm{~B}$ & $\mathrm{~B}$ & $\mathrm{~B}$ & $\mathrm{~B}$ & $\mathrm{~B}$ \\
\hline$N M$ & $\mathrm{~B}$ & $\mathrm{~B}$ & $\mathrm{~B}$ & $\mathrm{~B}$ & $\mathrm{~B}$ & $\mathrm{~B}$ & $\mathrm{~S}$ \\
\hline$N S$ & $\mathrm{~S}$ & $\mathrm{~S}$ & $\mathrm{~B}$ & $\mathrm{~B}$ & $\mathrm{~B}$ & $\mathrm{~S}$ & $\mathrm{~S}$ \\
\hline$Z E$ & $\mathrm{~S}$ & $\mathrm{~S}$ & $\mathrm{~S}$ & $\mathrm{~B}$ & $\mathrm{~S}$ & $\mathrm{~S}$ & $\mathrm{~S}$ \\
\hline$P S$ & $\mathrm{~S}$ & $\mathrm{~S}$ & $\mathrm{~B}$ & $\mathrm{~B}$ & $\mathrm{~B}$ & $\mathrm{~S}$ & $\mathrm{~S}$ \\
\hline$P M$ & $\mathrm{~S}$ & $\mathrm{~B}$ & $\mathrm{~B}$ & $\mathrm{~B}$ & $\mathrm{~B}$ & $\mathrm{~B}$ & $\mathrm{~S}$ \\
\hline$P B$ & $\mathrm{~B}$ & $\mathrm{~B}$ & $\mathrm{~B}$ & $\mathrm{~B}$ & $\mathrm{~B}$ & $\mathrm{~B}$ & $\mathrm{~B}$ \\
\hline
\end{tabular}

TABLE II. BASIS OF RULES FOR THE OUTPUT $K_{l}$

\begin{tabular}{|l|l|l|l|l|l|l|l|}
\hline de & $N B$ & $N M$ & $N S$ & $Z E$ & $P S$ & $P M$ & $P B$ \\
\hline$N B$ & $\mathrm{~B}$ & $\mathrm{~B}$ & $\mathrm{~B}$ & $\mathrm{~B}$ & $\mathrm{~B}$ & $\mathrm{~B}$ & $\mathrm{~B}$ \\
\hline$N M$ & $\mathrm{~B}$ & $\mathrm{~S}$ & $\mathrm{~S}$ & $\mathrm{~S}$ & $\mathrm{~S}$ & $\mathrm{~S}$ & $\mathrm{~S}$ \\
\hline$N S$ & $\mathrm{~B}$ & $\mathrm{~B}$ & $\mathrm{~S}$ & $\mathrm{~S}$ & $\mathrm{~S}$ & $\mathrm{~S}$ & $\mathrm{~S}$ \\
\hline$Z E$ & $\mathrm{~B}$ & $\mathrm{~B}$ & $\mathrm{~B}$ & $\mathrm{~S}$ & $\mathrm{~B}$ & $\mathrm{~B}$ & $\mathrm{~B}$ \\
\hline$P S$ & $\mathrm{~B}$ & $\mathrm{~B}$ & $\mathrm{~S}$ & $\mathrm{~S}$ & $\mathrm{~S}$ & $\mathrm{~B}$ & $\mathrm{~B}$ \\
\hline$P M$ & $\mathrm{~B}$ & $\mathrm{~B}$ & $\mathrm{~B}$ & $\mathrm{~S}$ & $\mathrm{~B}$ & $\mathrm{~B}$ & $\mathrm{~B}$ \\
\hline$P B$ & $\mathrm{~B}$ & $\mathrm{~B}$ & $\mathrm{~B}$ & $\mathrm{~B}$ & $\mathrm{~B}$ & $\mathrm{~B}$ & $\mathrm{~B}$ \\
\hline
\end{tabular}

Once the values $K_{p}$ and $K_{i}$ obtained the new parameters of the PI controller are calculated by the equations:

$$
\left\{\begin{array}{l}
K_{p}=\left(K_{p-\max }-K_{p-\min }\right) / K_{p}^{\prime}+K_{p-\min } \\
K_{i}=\left(K_{i-\max }-K_{i-\min }\right) / K_{i}^{\prime}+K_{i-\min }
\end{array}\right.
$$

\section{SimUlation RESUlT}

In this section, simulations are realized with a $7.5 \mathrm{KW}$ generator coupled to a $380 \mathrm{~V} / 50 \mathrm{~Hz}$ grid. Parameters of the machine are given in appendix A. With an aim to evaluate the performances of the three controllers: PI, SMC and AFLC, three categories of tests have been realized: pursuit test, sensitivity to the speed variation and robustness against machine parameter variations.

\section{A. Reference tracking}

The objective of this test is the study of the three controllers' behavior in reference tracking, while the machine's speed is considered constant and equal to its nominal value. The simulation results are presented in Fig. 7. As it's shown by this Figure, for the three controllers, the stator active and reactive powers tracks almost perfectly their references but with an important response time for the PI controller compared to the other controllers. On the other hand it can be noticed that the SMC ensures a perfect decoupling between the two axis, nevertheless a clear coupling effect is appear on the curves with PI and AFLC. Therefore it can be considered that the SMC have a very good performance for this test. In addition, through this same figure we notice that the two components of rotor current have forms that reflect Eq. 23.

\section{B. Sensitivity to the speed variation}

The aim of this test is to analyze the influence of a speed variation of the DFIG on active and reactive powers for the three controllers. For this objective and at time $=0.04 \mathrm{~s}$, the speed was varied from $150 \mathrm{rad} / \mathrm{s}$ to $170 \mathrm{rad} / \mathrm{s}$ (Fig. 8).

The simulation results are shown in Fig. 9. This figure express that the speed variation produce a slight effect on the powers curves of the system with PI and AFLC controllers, while the effect is almost negligible for the system with SMC one. It can be noticed that this last has a nearly perfect speed disturbance rejection, indeed; only very small power variations can be observed (fewer than 2\%). This result is attractive for wind energy applications to ensure stability and quality of the generated power when the speed is varying. 


\section{Robustness tests}

To test the robustness of the controllers used, parameters of the machine have been modified: the values of the rotor and the stator resistances $R_{r}$ and $R_{s}$ are multiplied by 2 , while the values of inductances $L_{r}, L_{s}$ and $M$ are divided by 2 . The machine is running at its nominal speed. The results presented
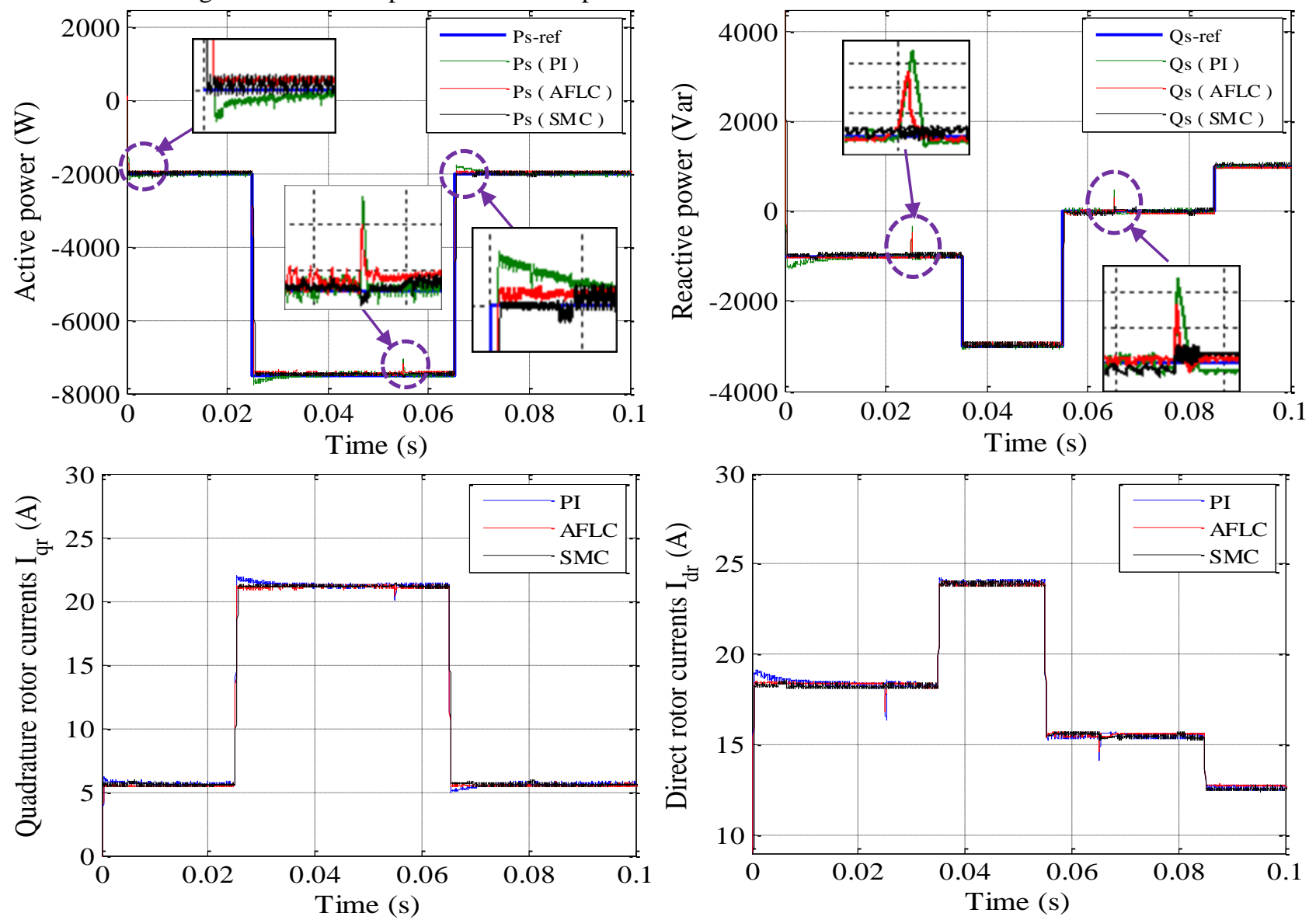

Fig. 7. Reference tracking test

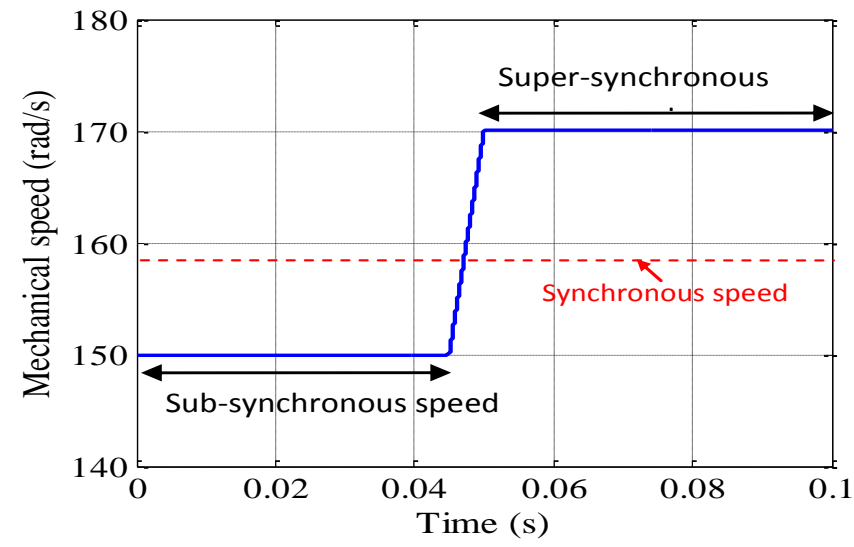

Fig. 8. Mechanical speed profile 


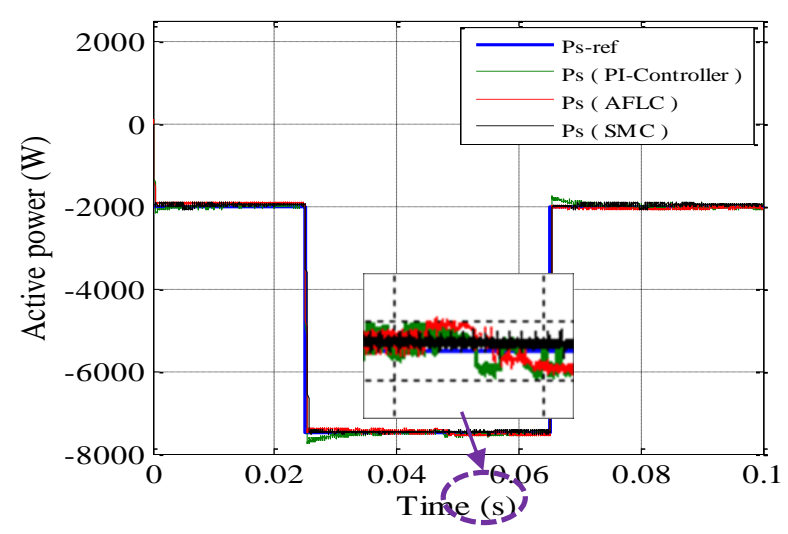

Fig. 9. Sensitivity to the speed variation

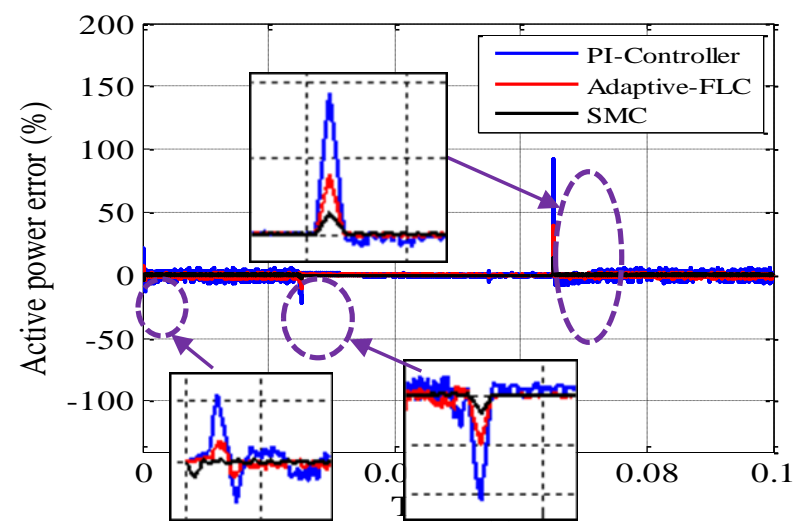

Fig. 10. Effect machine's parameters variation on the robust control of the DFIG

\section{CONCLUSIONS}

The modeling, the control and the simulation of an electrical power conversion system based on a DFIG connected directly to the grid by the stator and fed by a matrix converter On the rotor side has been presented in this paper. The objective was the implementation of a robust decoupled control the system of active and reactive powers generated by the side stator of the DFIG, to ensure of the high performance and a better execution of the DFIG, and to make the system insensible with the external disturbances and the parametric variations. In the first step, we started with a study of modeling on the matrix converter controlled by the Venturini modulation technique, because this later present a reduced harmonic rate and the possibility of operation of the converter at the input Unit power factor. The second step, we adopted a vector control strategy to control active and reactive power Exchanged between the stator of the DFIG and the grid. In third step, three different controllers are synthesized and compared. Regarding power reference tracking with the DFIG in ideal conditions, the SMC ensures a perfect decoupling between the two axes comparatively to the other controllers where the coupling effect between them is clear.

When the machine's speed is modified, a slight effect is appeared on the powers curves of the system with PI and
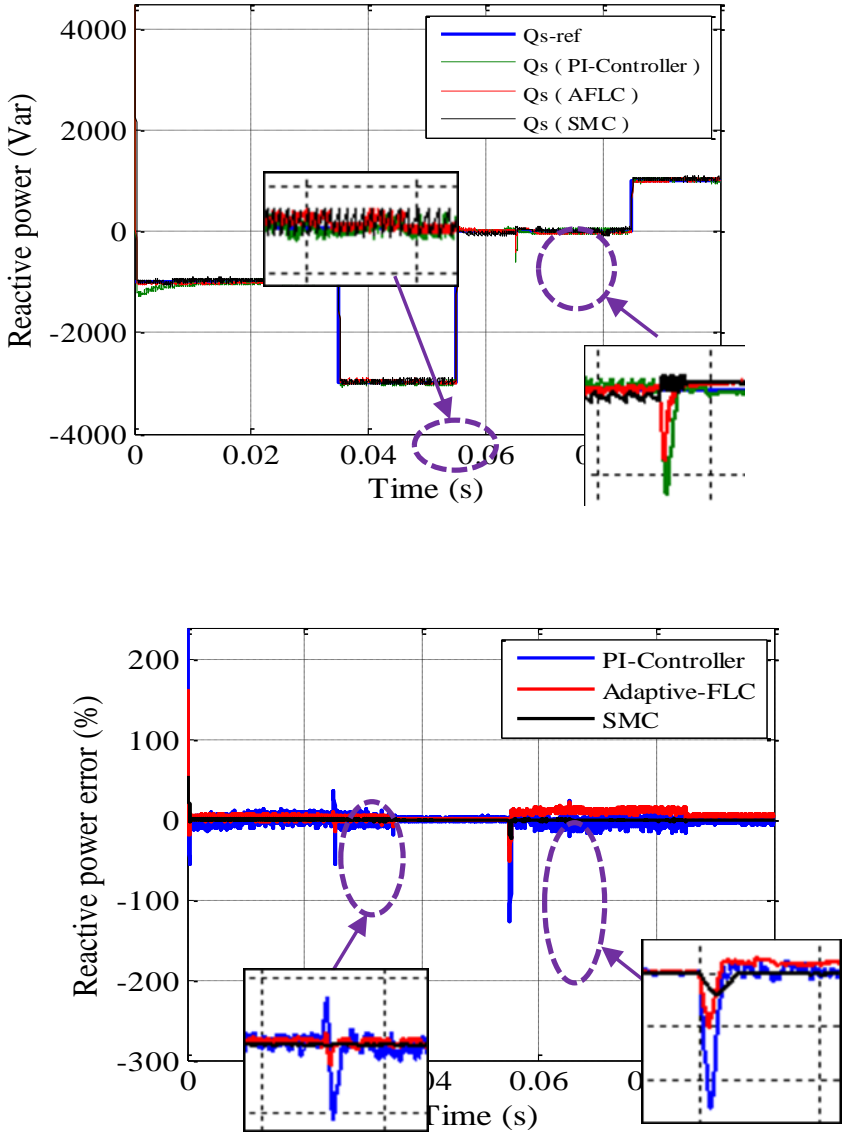

AFLC controllers, while the effect is almost negligible for a system with SMC one. A robustness test has also been investigated where the machine's parameters have been modified. These changes induce some disturbances on the power responses but with an effect almost doubled with the PI And AFLC controllers than on that with SMC one. Basing on all these results we conclude that robust control method as SMC can be a very attractive solution for devices using DFIG such as wind energy conversion systems.

APPENDIX

TABLE III. MACHINE PARAMETERS

\begin{tabular}{|l|l|l|}
\hline Parameters & Value & IS-Unit \\
\hline Nominal power & 7.5 & $\mathrm{KW}$ \\
\hline Turbine radius & 35.5 & $\mathrm{~m}$ \\
\hline Gearbox gain & 90 & \\
\hline Stator voltage & 398 & $\mathrm{~V}$ \\
\hline Stator frequency & 50 & $\mathrm{~Hz}$ \\
\hline Number of pairs poles & 2 & \\
\hline Nominal speed & 150 & $\mathrm{rad} / \mathrm{s}$ \\
\hline Rotor resistance & 0.62 & $\Omega$ \\
\hline Stator inductance & 0.084 & $\mathrm{H}$ \\
\hline Rotor inductance & 0.081 & $\mathrm{H}$ \\
\hline Mutual inductance & 0.078 & $\mathrm{H}$ \\
\hline Inertia & 0.01 & $\mathrm{Kg} . \mathrm{m}^{2}$ \\
\hline
\end{tabular}


TABLE IV. LIST OF SYMBOLS

\begin{tabular}{|l|l|}
\hline Symbol & Significance \\
\hline$V_{d s}, V_{q s}, V_{d r}, V_{q r}$ & Two-phase stator and rotor voltages, \\
\hline$\varphi_{d s}, \varphi_{q s}, \varphi_{d r}, \varphi_{q r}$ & Two-phase stator and rotor fluxes, \\
\hline$I_{d s}, I_{q s}, I_{d r}, I_{q r}$ & Two-phase stator and rotor currents, \\
\hline$R_{s}, R_{r}$ & Per phase stator and rotor resistances, \\
\hline$L_{s}, L_{r}$ & Per phase stator and rotor inductances, \\
\hline$M$ & Mutual inductance, \\
\hline$p$ & Number of pole pairs, \\
\hline$s$ & Laplace operator, \\
\hline$\omega_{s}, \omega_{r}$ & Stator and rotor currents frequencies (rad/s), \\
\hline$\omega$ & Mechanical rotor frequency (rad/s), \\
\hline$P_{s}, Q_{s}$ & Active and reactive stator power, \\
\hline$J$ & Inertia, \\
\hline$f$ & Coefficient of viscous frictions, \\
\hline$C_{r}$ & Load torque, \\
\hline$C_{e m}$ & Electromagnetic torque. \\
\hline
\end{tabular}

REFERENCES

[1] O. Anaya-Lara, N. Jenkins, J. Ekanayake, P. Cartwright, and M. Hughes,: Wind energy generation, In: Wiley, 2009.

[2] L. Empringham, J. W. Kolar, J. Rodriguez, P. W. Wheeler, and J. C. Clare,: Technological issues and industrial application of matrix converters: A review, In: IEEE Transactions on Industrial Electronics, vol. 60, no. 10, pp. 4260-4271, Oct. 2013.

[3] F. Poitiers, T. Bouaouiche, and M. Machmoum,: Advanced control of a doubly fed induction generator wind energy conversion, In: Electric Power Systems Research, 79 (2009) 1085-1096.

[4] J. P. da Costa, H. Pinheiro, T. Degner and G. Arnold,: robust controller for DFIGs of grid-connected wind turbines, IEEE Transactions on Industrial Electronics, Vol. 58, no. 9, September (2011) 4023-4038.

[5] M. A. Poller,: Doubly-fed induction machine models for stability assessment of wind farms, In: Power Tech Conference Proceedings, 2003, IEEE, Bologna, vol. 3, 23-26 June 2003.

[6] T. Brekken, N. Mohan,: A novel doubly-fed induction wind generator control scheme for reactive power control and torque pulsation compensation under unbalanced grid voltage conditions, In: IEEE 34th Annual Power Electronics Specialist Conference, 2003, PESC'03, vol. 2, pp. 760-764 15-19 June 2003.

[7] T. K. A. Brekken, N. Mohan,: Control of a doubly fed induction wind generator under unbalanced grid voltage conditions, In: IEEE Transaction on Energy Conversion, 129-135, 22 (March (1)) 2007.

[8] J. Lopez, P. Sanchis, X. Roboam, and L. Marroyo,: Dynamic behavior of the doubly fed induction generator during three-phase voltage dips, In: IEEE Transaction on Energy Conversion, 709-717, 22 (September (3)) 2007.

[9] T. Sun, Z. Chen, and F. Blaabjerg,: Flicker study on variable speed wind turbines with doubly fed induction generators, IEEE Transactions on Energy Conversion, 896-905, 20 (December (4)) 2005.

[10] M. A. A. Morsy, M. Said, A. Moteleb, and H. Dorrah,: Design and Implementation of Fuzzy Sliding Mode Controller for Switched Reluctance Motor, Proceedings of the International Multi-Conference of Engineers and Computer Scientists, Vol. 2, IMECS, Hong Kong, 19-21 March 2008.

[11] O. Barambones and J. M. Gonzalez de Durana,: An Adaptive Sliding Mode Control Law for the Power Maximization of the Wind Turbine System, In: 2011 International Conference on Power Engineering, Energy and Electrical Drives (POWERENG), pp. 1- 6, Spain (Malaga), 11-13 May 2011.

[12] E. S. Abdin, W. Xu,: Control design and Dynamic Performance Analysis of a Wind Turbine Induction Generator Unit, IEEE Trans. On Energy conversion, vol.15, No1, March 2000.

[13] M. Venturini,: A new sine wave in sine wave out conversion technique which eliminates reactive elements, In: Proc Powercon 7, San Diego, CA, pp. E3-1, E3-15, 27-24 March 1980.

[14] Z. Yan, C. Jin, and V. I. Utkin,: Sensorless sliding mode control of induction motors, In: IEEE Trans. Ind. electronic. 47 (2000).

[15] D. Kairous and B. Belmadani, Robust Fuzzy-Second Order Sliding Mode based Direct Power Control for Voltage Source Converter, International Journal of Advanced Computer Science and Applications (IJACSA), pp. 167-175, vol. 6, no. 8, 2015.

[16] Ou Sheng, Liu Haishan, Liu Guoying, Zeng Guohui, Zhan Xing, Wang Qingzhen, Liu Haishan, A Fuzzy PI Speed Controller based on Feedback Compensation Strategy for PMSM, International Journal of Advanced Computer Science and Applications (IJACSA), pp. 49-54, vol. 6 , no. $5,2015$. 